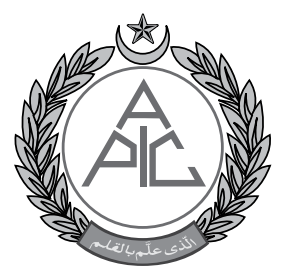

\title{
The impact of a simulation-based approach to teaching crisis resource management for medical emergencies on neonatal intensive care units in the UK, India, Nepal and Saudi Arabia
}

\author{
Syed Mohinuddin, ${ }^{1,2}$ Rajkumar Rajendram ${ }^{3,4}$ and Ravi Swamy ${ }^{5,6}$
}

\footnotetext{
'London Neonatal Transport Service, Barts Health NHS Trust, London, (UK)

${ }^{2}$ Department of Neonatal Intensive Care, King Abdulaziz Medical City, Riyadh, (Saudi Arabia)

${ }^{3}$ Department of Anaesthesia and Intensive Care, Stoke Mandeville Hospital, Aylesbury, (UK)

${ }^{4}$ Department of Medicine, King Abdulaziz Medical City, Riyadh, (Saudi Arabia)

${ }^{5}$ Centre for Perinatal

Neuroscience, Imperial College

London, London, (UK)

${ }^{6}$ Department of Neonatology,

Imperial College Healthcare

NHS, London, (UK); and Manipa

Hospitals, Bengaluru, (India)

\section{Correspondence:}

Dr Syed Mohinuddin,

Consultant in Neonatal

Intensive Care, London

Neonatal Transport Service,

Barts Health NHS Trust, London

(UK); E-mail:

Syed.Mohinuddin@nhs.net

Received: 01 Oct 2018

Reviewed:

8 Oct, 10 Nov 2018

Accepted: 10 Nov 2018
}

\begin{abstract}
Effective communication, team working and human factors are given little attention in traditional medical curricula. However, these skills are fundamentally important during crisis resource management (CRM) in healthcare. These skills can be learnt and can be taught very effectively within a simulated environment. Thus simulation-based training on CRM can positively impact patient safety. One such course which focuses on the management of common neonatal emergencies is the 'Neonatal Emergencies Simulation Team training' (NEST) program. This one day multiprofessional educational program, originally designed by the London Neonatal Transfer Service, aims to develop multidisciplinary confidence and competence in the management of common neonatal emergencies. This program has been evaluated positively in India, Nepal, Saudi Arabia and the UK and shows promise for wider implementation in high-, middle- and lowincome countries. Here we give an overview of the program and its implications.
\end{abstract}

Key words: Communication; Team work; Human factors; Crisis Resource Management; Simulation; Neonatal emergencies

Citation: Mohinuddin S, Rajkumar Rajendram R, Swamy S. The impact of a simulationbased approach to teaching crisis resource management for medical emergencies on neonatal intensive care units in the UK, India, Nepal and Saudi Arabia. Anaesth Pain \& Intensive Care 2018;22(3 Suppl1):S124-S128

\section{INTRODUCTION}

Guided, controlled, interactive experiences (i.e. simulation-based training) evokes or replicates substantial aspects of the real world and can supplement or amplify experiences gained. ${ }^{1}$
Simulation-based training is used to train professionals in many disciplines where life or death decisions may have to be made within seconds and situational awareness is critically important. Each of these professions (e.g. aviation, traffic management, 
and military strategy) uses simulation-based training in different forms and for various purposes. ${ }^{2}$

In healthcare, simulation facilitates learning and can be used to manipulate operational models on a fundamental level. ${ }^{3}$ Such training can increase the level of confidence and competence of healthcare professionals and contributes toward achieving high quality patient care. 4,5

The knowledge and skills required to manage medical emergencies remain relatively constant. So the emphasis of team training should be on human factors (i.e. leadership, communication skills, teamwork and situational awareness). This can be best delivered by a simulation-based interface. ${ }^{6-8}$

\section{SIMULATION TO TEACH NICU CRM IN THE UK}

The use of simulation to teach the skills needed for effective neonatal resuscitation and crisis resource management $(\mathrm{CRM})$ in the neonatal intensive care unit (NICU) has exploded in high-income countries. ${ }^{9}$ An example of one such course taught in the United Kingdom (UK) is the 'Neonatal Emergencies Simulation Team' training (NEST) program.

The NEST course is a 1-day multidisciplinary educational program for all healthcare professionals who are involved in the management of neonatal emergencies. The key objective of this course is to improve participants' confidence and competence in the management of common neonatal emergencies working in a multidisciplinary team. This wellrecognized course is run by the Neonatal Transport Service (NTS), London.

A typical NEST course has 24-28 candidates with a doctor-to-nursing ratio of 4-5:2. Participants include postgraduate trainees in neonatology, consultant pediatricians and neonatologists, and nurses with a variable range of neonatal care experience from 6 months to 20 years.

The candidates are divided into 4 groups of 6-7, each with a mix of nurses and doctors as in reallife situations. The course begins with a lecture to introduce participants to the importance of human factors in CRM during medical emergencies. The faculty then demonstrate management of a neonatal emergency within a simulated clinical environment to the candidates who are then immersed in simulation sessions and workshops throughout the rest of the day.

A simulation exercise is an activity resembling a clinical situation. Participants role play the part of medical care providers. Simulation scenarios in the
NEST course include the management of preterm and term babies at the time of birth, meconium aspiration syndrome; and other common and rarer clinical emergencies, such as necrotizing enterocolitis and congenital diaphragmatic hernia. Communication and handover during emergencies are emphasized using the 'structured situation-backgroundassessment-recommendation' (SBAR) tool.

In each simulation exercise participants are sequentially challenged with multiple stimuli. These are presented as multimodal quanta of patient data in various forms (e.g. findings of history taking and physical examination, continuous monitoring of vital signs, laboratory data, and blood gas analyses). The participants must interpret and act on this data as they would in real life.

The progression of the simulation exercise is manipulated by a facilitator towards any of a range of pre-defined outcomes chosen mainly for educational impact. The candidates are then debriefed using the Harvard method. The main aim of the debriefing is to facilitate participants' reflective practice to draw conclusions on the human factors which affected their performance. ${ }^{10}$ This reflective practice should enhance professional effectiveness. ${ }^{10}$

Simulation scenarios utilize standard neonatal equipment; Newborn HAL ${ }^{\circledR}$ S3010 (Guamard Scientific Inc., FL, USA), Resusci Baby ${ }^{\circledR}$ (Laerdal Medical, UK), and preterm manikin (Adam Rouilly, Kent, UK). The software used is from Guamard Scientific (USA) and Castle Andersen ApS, Denmark. Hardware consisted of tablet computers from Motion Computing ${ }^{\circledR}$ (Austin, TX, USA) and Apple ${ }^{\circledR}$ (CA, USA). Disposable equipment is provided to allow real-time performance of procedures such as umbilical vein cannulation and endotracheal intubation in manikins. With this range of high-fidelity simulators and equipment, the faculty are able to create a fully immersive simulated clinical experience for the teams of participants.

The NEST faculty use the well-described 3-step approach to high-fidelity simulation education. ${ }^{11,12}$ At first, participants are introduced to the physical space and high-fidelity manikin by a faculty demonstration. Structured ice-breaking techniques are then used to encourage participants to bond within their teams before immersing them into highfidelity simulation. In the final and most important step, the faculty facilitate a structured debrief of the teams' performance. This debrief has a clear emphasis on an andragogic approach and its underpinning educational theory. ${ }^{13,14}$ 
The course is built upon a cross over model to improve clinical handovers. Each of the 4 groups involved in simulation handover to another group using the SBAR tool. ${ }^{15}$ At the end of this handover, they share the key learning points they realized during the facilitated debrief of their session. This maximizes the learning and also the exposure to cases by each group. ${ }^{16}$

The main focus of the course is to offer participants opportunities to develop nonclinical skills in teamwork and crisis resource management. However, participating in the process of case-based simulation also reinforces the knowledge and core skills the candidates require to manage neonatal emergencies.

The objectives of the NEST course are met by combining the credibility and expertise of the faculty with high-fidelity equipment to immerse the participant teams in a believable simulated clinical setting. Thereby the faculty can deliver the briefing, role-play, debriefing, and formulation of action plans required to complete the whole package of simulationbased training. ${ }^{17,18}$

Whilst well established in high-income countries, simulation remains a relatively novel teaching modality in low- and middle-income countries (LMICs) like India and Pakistan. Traditional undergraduate curricula for training medical and nursing professionals in LMIC have limited emphasis on human factors. Post-graduate training also focuses on knowledge and clinical skills. Simulation-based training could enhance the training of professionals working on neonatal units in LMIC.

\section{SIMULATION TO TEACH NICU CRM OUTSIDE THE UK}

The London 'Neonatal Emergencies Simulation Team' training (NEST) program has already been adapted and delivered in centers throughout India, Nepal and Saudi Arabia.

\section{The NEST Saudi Arabia Experience}

The modification of London NEST program for delivery in Riyadh, Saudi Arabia was relatively straightforward. The resources available within a typical hospital or medical city in Riyadh are very similar to those available in the UK. To develop NEST Saudi Arabia, a group of Saudi neonatologists collaborated with colleagues from the UK to adapt the course to NICU practice in Saudi Arabia. One major difference from UK practice is the presence of respiratory therapists in the NICU team in Riyadh. Respiratory therapists were, therefore, invited to attend NEST Saudi Arabia. Clinical simulation case scenarios were adapted to include a role for these non-medical specialists in airway management, ventilation and chest physiotherapy. Scenarios on end-of-life communication were also adapted to reflect cultural sensitivities.

Since 2017 faculty from the London course have taught NEST in Riyadh alongside senior Saudi pediatricians/neonatologists and NICU nurses who had been taught simulation training in Saudi Arabia by the faculty from the London course. The NEST Saudi Arabia faculty were briefed and debriefed before and after the course by the NEST faculty from the UK. This creates a cohesive atmosphere which facilitates the delivery of a high-quality participant experience.

\section{The NEST India and NEST Nepal Experience}

To develop NEST India, a group of Indian neonatologists collaborated with colleagues from the United Kingdom (UK) to adapt the NEST London course to NICU practice in India and Nepal. The simulation case scenarios used in NEST London had to be significantly adapted for use in India and Nepal. The cases had to reflect the resources available within a typical Indian healthcare facility. The resources available within a typical Nepalese healthcare facility are similar to those in India.

By modification of the London NEST course to suit the needs of the Indian and Nepalese settings, the NEST India and NEST Nepal courses were created. All the teaching material was adapted to reflect current professional practice in India and Nepal. The NEST India course was introduced in collaboration with London NTS and the National Neonatology Forum of India. Since November 2014 members of the faculty from the London course have taught NEST courses in India alongside senior Indian pediatricians/neonatologists who had been trained in simulation training in the UK.

The first NEST Nepal course was delivered in 2017, and was run on similar lines as laid down for the NEST India.

The NEST India and NEST Nepal faculty were briefed and debriefed before and after the course by the NEST faculty from the UK to create a cohesive environment which is much needed to facilitate the delivery of a high-quality participant experience.

\section{EVALUATION OF THE IMPACT OF SIMULATION-BASED TRAINING ON NICU CRM IN INDIA}

There are limited data on the use of simulation training for neonatal emergencies in LMIC. Swamy 
et al. ${ }^{19}$ systematically evaluated the impact of simulation-based training on NICU CRM on learners in India. They analyzed a total of 191 feedback forms (58 nurses; 133 doctors) from NEST India courses conducted at 4 centers in India. Participants' selfreported pre- and post-course feedback showed significant improvement. This improvement was consistent across all domains. Course feedback was also consistent between centers. The evaluation by Swamy et al. ${ }^{19}$ demonstrates the efficacy of NEST courses in India. NEST India showcases the pioneering effort by neonatal pediatricians in a lowincome country. It demonstrate that the NEST course is highly relevant to the Indian neonatologists' and NICU nurses' educational needs. The participants' evaluation suggests that the course is highly effective in empowering them to deal with neonatal emergencies. The feedback also showed a significant improvement in the candidate's ability to approach and communicate during emergencies. Most of the candidates appreciated the learning opportunity during the NEST course.

The rigid hierarchical structure of healthcare professionals in India often limits nurses' roles. It is therefore, not surprising that nurses' feedback on their NEST India experience highlighted their feeling of empowerment and integration into the team. ${ }^{19}$ This was a significant achievement as working in teams and harnessing the valuable experience of these healthcare professionals is critically important for improving neonatal care. Similar themes were noted in the feedback comments from participants at all canters. This suggests that a wide range of Indian healthcare professionals perceived that the training they received during NEST India was effective and relevant to NICU practice in India.

The data presented by Swamy et al, ${ }^{19}$ are similar to those described in previous studies which showed that high-fidelity simulation allows participants to practice their skills in communication, assessment, diagnosis, and treatment, as well as teamwork. ${ }^{20,21}$ Knowledge is gained when candidates develop their own hypotheses and test these against their current understanding. ${ }^{22,23}$ High-fidelity simulation can be seen as a constructivist mechanism. It allows the learner to actively create knowledge based on the interaction with their environment during the learning session.

\section{LIMITATIONS}

The modifications done in the course for the delivery in India and Nepal have not been as a description of these was not the objective of this paper.

Numerical data regarding the effectiveness of the program would be more appropriate, and future studies might be conducted as the program progresses at a wider scale. The study was also limited in because of involvement of only neonatal Intensive care staff and scenarios.

\section{CONCLUSION}

The use of simulation to teach skills needed for effective neonatal resuscitation and CRM in NICU is well established in high-income countries. The use of high-fidelity simulation-based training for CRM in NICU is gaining ground in LMIC. Participants in the UK, Saudi Arabia, India and Nepal have consistently reported significant improvements to their confidence to use of a structured approach, manage simulated neonatal emergencies and their ability to effectively communicate using the SBAR tool. The NEST course therefore shows promise for wider implementation in high-, middle- and lowincome countries. This should improve patient safety and experience. Long term studies are planned to evaluate these hypothesis.

Conflicts of interest: SM, RR and RS have all taught and received honoraria for teaching the NEST course in the UK, Saudi Arabia and India.

Authors' contribution: SM, RR and RS have all equally contributed in the program as well as in preparation of this manuscript. 


\section{REFERENCES}

1. Gaba DM. The future vision of simulation in health care. Qual Saf Health Care. 2004;13(suppl 1):i2-10. [PubMed] [Free full text]

2. Reason J. Human error: models and management. BMJ. 2000;320(7237):768-770. [PubMed] [Free full text]

3. Issenberg SB, McGaghie WC, Petrusa ER, Lee Gordon D, Scalese RJ. Features and uses of high-fidelity medical simulations that lead to effective learning: a BEME systematic review. Med Teach. 2005;27:10-28. [PubMed]

4. Ahmed A, Moore H, Purva M, Clark S. G14(P) What do senior paediatric trainees want from simulation in Yorkshire? Training needs assessment survey. Arch Dis Child. 2013;98 (suppl 1): A11-A13.

5. Blackwood J, Duff JP, Nettel-Aguirre A, Djogovic D, Joynt C. Does teaching crisis resource management skills improve resuscitation performance in pediatric residents? Pediatr Crit Care Med. 2014;15:e168-e174. [PubMed]

6. Hogan MP, Pace DE, Hapgood J, Boone DC. Use of human patient simulation and the situation awareness global assessment technique in practical trauma skills assessment. J Trauma. 2006;61:1047-1052. [PubMed]

7. Adler MD, Trainor JL, Siddall VJ, McGaghie WC. Development and evaluation of high-fidelity simulation case scenarios for pediatric resident education. Ambul Pediatr. 2007;7:182-186. [PubMed]

8. Falcone RA, Jr, Daugherty $M$,
Schweer L, Patterson M, Brown RL, Garcia VF. Multidisciplinary pediatric trauma team training using high-fidelity trauma simulation. J Pediatr Surg. 2008;43:1065-1071. [PubMed]

9. Grant DJ, Marriage SC. Training using medical simulation. Arch Dis Child. 2012;97:255-259. [PubMed]

10. Rudolph JW, Simon R, Rivard P, Dufresne $R L$, Raemer DB. Debriefing with good judgment: combining rigorous feedback with genuine inquiry. Anesthesiol Clin. 2007;25:361-376. [PubMed]

11. Yaeger KA, Halamek LP, Coyle M, Murphy A, Anderson J, Boyle K, et al. High-fidelity simulation-based training in neonatal nursing. Adv Neonatal Care. 2004:4:326-331. [PubMed]

12. Clerihew L, Rowney D, Ker J. Simulation in paediatric training. Arch Dis Child Educ Pract Ed. 2016;101:8-14. [PubMed] [Free full text]

13. Kolb DA. Experiential learning: experience as the source of learning and development. Englewood Cliffs, $\mathrm{NJ}$ : Prentice Hall. 1984;1.

14. Gibbs G. Learning by doing: a guide to teaching and learning methods. Oxford: Further Education Unit Oxford

15. Kipnis G. Collaborative communication: integrating SBAR to improve quality/patient safety outcomes. J Healthc Qual. 2009;31:19-28. [PubMed]

16. World Health Organization. Learning from error. Patient Safety Workshop. Geneva: World Health Organization; 2008.

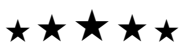

17. Aggarwal R, Mytton OT, Derbrew M, Hananel D, Heydenburg M, Issenberg $B$, et al. Training and simulation for patient safety. Qual Saf Health Care. 2010;19(suppl 2):i34-i43. [PubMed]

18. Harris T. I'm OK-You're OK. New York, NY: Harper Collins; 2004.

19. Swamy R, Chandrasekaran M, Venkatagiri PK, Grover A, Datta V, Sinha $A$ and Mohinuddin S. Multidisciplinary neonatal emergencies simulation team-training (nest) improves participant's confidence in dealing with simulated neonatal emergencies. Journal of Neonatology 2018; (in press).

20. Cates LA, Wilson D. Acquisition and maintenance of competencies through simulation for neonatal nurse practitioners: beyond the basics. Adv Neonatal Care. 2011;11:321-327. [PubMed]

21. Ericsson KA. Deliberate practice and the acquisition and maintenance of expert performance in medicine and related domains. Acad Med. 2004;79(10 Suppl):S70-S81. [PubMed]

22. Parker BC, Myrick F. A critical examination of high-fidelity human patient simulation within the context of nursing pedagogy. Nurse Educ Today. 2009;29:322-329. [PubMed]

23. Carapiet D, Fraser J, Wade A, Buss $P W$, Bingham R. Changes in paediatric resuscitation knowledge among doctors. Arch Dis Child. 2001;84:412414. [PubMed] [ree full text] 